Article

\title{
Sustainable Corporate Social Media Marketing Based on Message Structural Features: Firm Size Plays a Significant Role as a Moderator
}

\author{
Moon Young Kang and Byungho Park * $\mathbb{D}$ \\ KAIST College of Business, Korea Advanced Institute of Science and Technology(KAIST), 85 Hoegi-ro, \\ Dongdaemun-gu, Seoul 130-722, Korea; mkang@business.kaist.ac.kr \\ * Correspondence: mediapark@kaist.ac.kr; Tel.: +82-2-958-3514
}

Received: 18 March 2018; Accepted: 10 April 2018; Published: 13 April 2018

\begin{abstract}
Social media has been receiving attention as a cost-effective tool to build corporate brand image and to enrich customer relationships. This phenomenon calls for more attention to developing a model that measures the impact of structural features, used in corporate social media messages. Based on communication science, this study proposes a model to measure the impact of three essential message structural features (interactivity, formality, and immediacy) in corporate social media on customers' purchase intentions, mediated by brand attitude and corporate trust. Especially, social media platforms are believed to provide a good marketing platform for small and medium enterprises (SMEs) by providing access to huge audiences at a very low cost. The findings from this study based on a structural equation model suggest that brand attitude and corporate trust have larger impacts on purchase intention for SMEs than large firms. This implies that SMEs with little to no presence in the market should pay more attention to building corporate trust and brand attitude for their sustainable growth.
\end{abstract}

Keywords: structural feature; social media; small and medium enterprise; SME; sustainability; message attribute; marketing; structural equation model

\section{Introduction}

Technology has changed the way people communicate and make decisions [1]. The high penetration rate of the Internet has led people to initiate new types of social interaction. For example, social media sites such as Twitter and Facebook are now popular tools for everyday communications. One study that surveyed Fortune 500 companies reported that $77 \%$ have active corporate Twitter accounts, and 70\% have Facebook accounts [2]. Social media marketing has become an emerging trend for firms as a cost-effective tool to build their brand image and to enrich customer relationships. In addition, social media has been adopted as a part of companies' integrated marketing communication strategy and as a new way of managing public relations. As relationship marketing is defined as a process of identifying, establishing, maintaining, enhancing, and terminating relationships with customers [3], within this context, corporate communication efforts via social media often take the form of relationship marketing and are recognized as a revolutionary way to build relationships with customers for sustainable growth. In addition, social media are believed to provide a good marketing platform for small and medium enterprises (SMEs) by providing access to huge audiences at a very low cost.

As opposed to the rapid speed of technological advances, the importance of the message itself is often neglected by business practitioners and academics. This study attempts to apply findings from communication science to corporate social media marketing. In marketing communication, 
the content of the message plays an important role in the formation of a customer's attitude toward the message source, which is corporate. Since language is used as a vehicle, linguistic structural features of the language used become attributes of the message. For example, how formal the language is, and what kind of vocabulary is used, are likely to affect customers in a number of ways. According to the literature in communication research, there are many structural features in text messages: the type of punctuation marks, symbols, and abbreviations used, as well as the font type, color, and size are a few examples. These features are likely to affect the way messages are processed, as message receivers are affected by the features both cognitively and emotionally [4]. For this reason, without strategically managing these message structural features for corporate social media, it is impossible to acquire and maintain customers in a sustainable manner. The objective of this research is to develop a model to examine the impact of three essential message attributes (interactivity, formality, and immediacy) in social media on customers' purchase intentions mediated by brand attitude and corporate trust. In addition, this research investigated the moderating effect of firm size (publicly known large corporates vs. unknown small and medium enterprises). This investigation is especially meaningful for the sustainability of SMEs (small and medium enterprises) as it has been argued that "some theories, tools and techniques of marketing are not as relevant or useful to SMEs in application" [5]. Previous research found that firm size affects variables such as trust and behavioral intent [6], but to the best of our knowledge there have been no other studies regarding whether and which particular message structural features in marketing communication are more effective for SMEs.

To summarize, this study intends to find whether message structural features used in corporate social media can affect corporate trust and brand attitude, and ultimately influence customers' purchase intention. Based on a structural equation model, this research provides managerial implications by proposing effective communication styles on forming sustainable corporate trust, brand attitude, and purchase intention. This study also provides guidelines on whether structural features work differently for large, established firms versus SMEs. Given the lack of literature on the relationship between message attributes and brand attitude, findings from this study are expected to fill the gap in the literature. In addition, considering that SMEs play an essential role in the global economy through innovation and job creation [7], this study is particularly meaningful for sustainability of modern society.

The rest part of the paper is organized as follows: first, we review the relevant literature. Next, we describe the study design including measurement and data collection. Then, we discuss the results from empirical analysis using a structural equation model and managerial implications for SMEs for their sustainable growth.

\section{Theoretical Development}

\subsection{Interactivity}

According to communication science, interactivity is one of the structural features that may be found in a mediated message [8]. The literature on interactivity in communications covers a broad range of phenomena, such as human-to-human interaction (messages/signals are produced by humans on both sides) and human-to-system interaction (system providing feedback according to human's input, which is often limited in variety and depth of responses), and whether the communication is mediated or not. This study focuses only on human-to-human interaction, mediated by information technology, which is regarded as a higher level of interactivity than human-to-system interaction [9].

According to the e-business literature, customer relationship management (CRM) is an integration of technologies and business processes, whose goal is to satisfy customers with their needs during any given interaction [10]. As customer interaction is one of the key processes in CRM, many companies struggle with how to implement new media using information technology for their customer interaction in a cost-effective and ubiquitous manner. As a matter of fact, the distinct difference between traditional mass media (e.g., newspaper, radio, and broadcast TV) and the new media 
is the "interactivity" [11]. According to Downes and McMillan, interactivity increases when communication is two-way and the communication timing is kept flexible enough to meet the needs of the communication [12]. It is also found that interactivity has the potential to influence brand-building, since interactivity refers to the processes of forming relationships among customers, the company, and its brand [13]. At the center of the relationship, there is trust, which is particularly critical to most sales transactions [14]. This study focuses on corporate trust, which stems from the perceived or actual relationships between firms and customers. Research in psychology and marketing demonstrates how trust is formed as relationships become closer, and vice versa [15]. Social communication, which facilitates relationships, also facilitates trust; this is especially the case in a relationship based on computer-mediated communication [16]. While much is known about interactive communication and trust, little is known about interactivity and brand attitude except that brand attitude and corporate trust are likely to correlate. Therefore:

Hypothesis 1(H1). Corporate trust will be more positive (negative) when a firm is more (less) willing to engage in interactive communications via social media with its customers.

Research Question 1: Will brand attitude be affected by firm's efforts to engage in interactive communications via social media with its customers?

\subsection{Linguistic Formality}

Variation in language formality occurs when one expresses an idea in different ways, usually when addressing different audiences [17]. The use of formal language involves purposeful and overt demonstrations of respect for the addressee through establishing seriousness and politeness [18]. On the contrary, the use of informal language (such as slang or less elegant vocabulary) may signal the addresser's wish to establish a closer relationship, even if it lacks seriousness and shows less respect toward the addressee to a certain degree (which depends on how informal the language is used). For such reasons, formal language is chosen when the speaker intends to facilitate smooth social relationships [19]. For example, a study involving meta-discourse in CEOs' letters concluded that CEOs using formal language were perceived as competent and trustworthy because formal language usage elicits a sense of confidence and trust in shareholders and potential investors [20]. Likewise, formal language influences consumers as they attempt to reduce risk and establish confidence in their decision making [21]. Again, given that little is known about linguistic formality and brand attitude, the following hypothesis and research question are proposed:

Hypothesis 2(H2). Corporate trust will be more positive (negative) when the messages via social media are perceived to be more formal (informal or casual) than when they are perceived to be informal (formal).

Research Question 2: Will brand attitude be affected by how formally perceived the messages via social media are?

\subsection{Immediacy}

Immediacy measures the psychological distance between the speaker and the audience, as it enhances closeness and nonverbal interaction with one another [22]. Gunawardena and Zittle suggest that immediacy can be conveyed nonverbally by cues such as physical proximity and facial expressions [23]. Some of the examples that reveal immediacy include smiling, gesturing, and eye contact [24]. Doney and Cannon also argue that social interaction can engender trust, which is likely to lead to an increase in intentions to purchase for the customer [6]. In the context of social media, immediacy can be deployed with private talk to reduce personal distance and/or the use of the emotional lexicon (a.k.a., emoticons) to express emotion or facial expressions [25]. Messages that promote immediacy are not business-oriented in nature, and are meant to be more enjoyable than 
other serious messages. A user's enjoyment of information systems is known to have a generally positive effect on trust [26]. As personal friendships and customers' perceived closeness to a firm and its staff might increase brand loyalty and enhance such relationships [27], it is possible to postulate that immediacy influences brand attitude and corporate trust as follows:

Hypothesis 3(H3). Corporate trust will be more positive (negative) when there is (no) immediacy in messages via social media.

Research Question 3: Will brand attitude be affected by the level of immediacy in the firm's messages via social media?

\subsection{Behavioral Outcomes: Purchase Intention}

Purchase intention is important because it is highly correlated with actual purchase behavior [28]. Favorable brand relationships affect the purchase decisions of customers [29]. In particular, Homer asserts that consumers' attitudes toward brands can be transferred to their attitudes toward products, which thus affect consumers' choices in their purchase decisions [30]. From an information-processing viewpoint, customers making purchases under uncertain circumstances are likely to search for product information until they feel comfortable about making a decision, and the brand of a product or service serves as a cue that influences this decision [31], which is the mechanism of attitudes toward brands mediating purchase intentions.

As a mediating factor, corporate trust also plays an important role in purchase intention. Research has found positive influences of trust on purchase intentions and actual purchase decisions [32]. To put argument within the context of corporate trust, the notion of trust refers to a set of beliefs about the company (the trustee), which leads the customer (the trustor) to assume that the company's actions will have positive consequences for the customer [33]. Corporate trust formed through this mechanism influences the purchase intentions of consumers by promoting personal connections between customers and company or brands [34]. Consistent with the literature, it is predicted that brand attitudes and corporate trust affect the purchase intentions of consumers as follows:

Hypothesis 4a(H4a): Purchase intentions will be higher (lower) when consumers have (un)favorable brand attitudes.

Hypothesis 4(H4b): Purchase intentions will be higher (lower) when consumers have strong (weak) corporate trust.

\subsection{Firm Size as a Moderator}

The literature on small and medium enterprises (SMEs) suggests that conventional or formal marketing approaches are not appropriate for SMEs, primarily due to the constraints in their resources [5,35]. In the minds of consumers, firm size can be an indication of how well it can compensate them in the case of product or service failure [36]. Therefore, firm size affects how they form trust toward the firm, as well as their purchase intentions [6].

While research in communication science provides knowledge on psychological effects of message attributes, little, if any, is known how firm size will interact with them. Will the effect of using formal/informal language on corporate trust be larger for well-known, established companies or brand new companies? If interacting with others lead to change in brand attitude, will firm size make a difference to this change? Hence the following research questions are devised:

Research Question 4: Will firm size have any effect on the impact of interactivity on corporate trust (RQ4a) and/or brand attitude (RQ4b)? 
Research Question 5: Will firm size have any effect on the impact of formality on corporate trust (RQ5a) and/or brand attitude $(R Q 5 b)$ ?

Research Question 6: Will firm size have any effect on the impact of immediacy on corporate trust (RQ6a) and/or brand attitude (RQ6b)?

Research Question 7: Will firm size have any effect on the impact of corporate trust (RQ7a) and brand attitude (RQ7b) on purchase intention?

\section{Experimental Design and Data Collection}

To test the proposed hypotheses and answer the research questions, we designed and implemented a study using Twitter. Twitter lets its users write messages ("tweets") within a limit of 140 characters, either publicly or privately. Public messages are displayed on the screen of users who subscribe to the writer's account ("followers"). In Twitter, one can address another user by including the user's ID in their messages ("mentioning") — the creation of such messages are notified to the target user by the system, but it is also accessible by anyone who browses the writer's account.

A total of 200 college students in Daejeon, Korea, having prior experience using Twitter, participated in this experiment for cash (KRW 20,000, equivalent to USD 18.00). The mean age of the subjects was 23.7 years (S.D. $=3.9$ ), and $58 \%$ were male. The experiment was conducted in a laboratory equipped with four desktop computers. Upon arrival, the subjects were instructed to complete an online survey. After the experiment was over, the subjects were debriefed, thanked, and dismissed.

\subsection{Experimental Design}

The manipulated stimuli were created by using a factorial design of firm size (2: large vs. SMEs) $\times$ interactivity (2: with interactivity vs. without interactivity) $\times$ formality $(2:$ with formality vs. without formality) $\times$ immediacy (2: with immediacy vs. without immediacy). Firm size was a between-subjects factor and the rest were within-subjects factors. That is, each subject was exposed to 8 (=interactivity (2) $\times$ formality (2) $\times$ immediacy (2)) different corporate Twitter profiles in total. Among the 200 respondents, half of them were randomly assigned to evaluate large firms, and the remaining half were assigned to evaluate SMEs: the industry where these firms came from was limited to the information technology/high-tech sector in order to control for industry-specific effects. Among 1600 (=200 participants $\times 8$ corporate Twitter profiles) observations, two had defects (i.e., missing values) and 1598 observations (half for large firms and the remaining half for SMEs) were analyzed to test the proposed model. Eight Tweet messages for each company were shown on one screen as a stimulus, as shown in Figure 1 in random order. The presentation order of companies was also randomized for each participant.

There were two levels for interactivity. For the with-interactivity level, three of the eight messages were written as a response to a specific user on Twitter with the use of the "mentioning" function (quoting the other user's name and his/her message in the response). All responding messages took the form of answering another user's question. In an effort to make the messages look realistic, the other five messages were created as statements, usually about the company's product or other subjects, depending on the condition. Hence, the study participants would see the company doing its normal marketing activity and would occasionally respond to other (potential) consumers. For the without-interactivity level, all messages were statements without "mentioning" function.

There were two levels of formality. Since this experiment used Korean language, the level of formality was manipulated by having verbs written either in Hapsyo-che, which is most formal, or Heyo-che, which is less formal than the other type, but still polite [37]. 


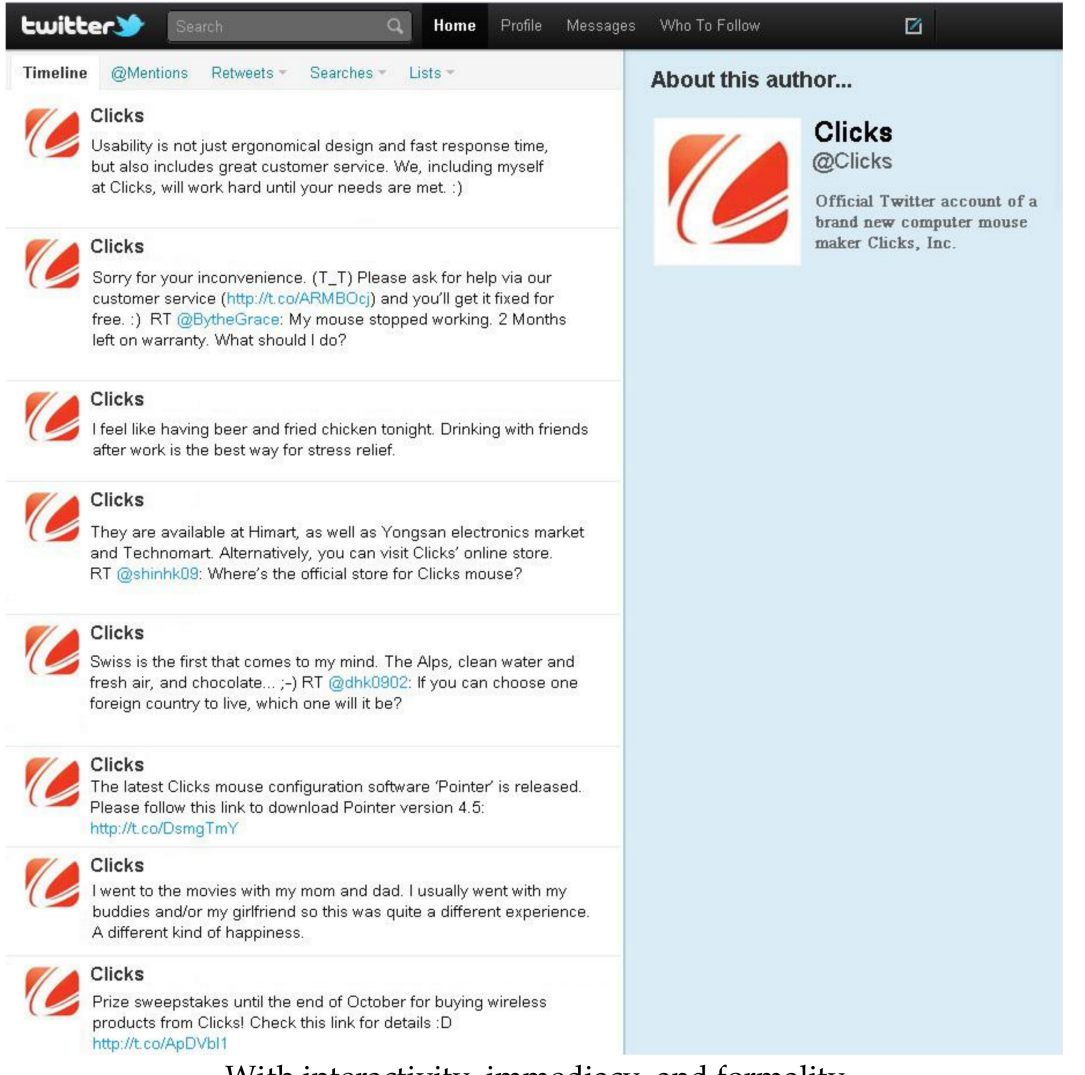

With interactivity, immediacy, and formality

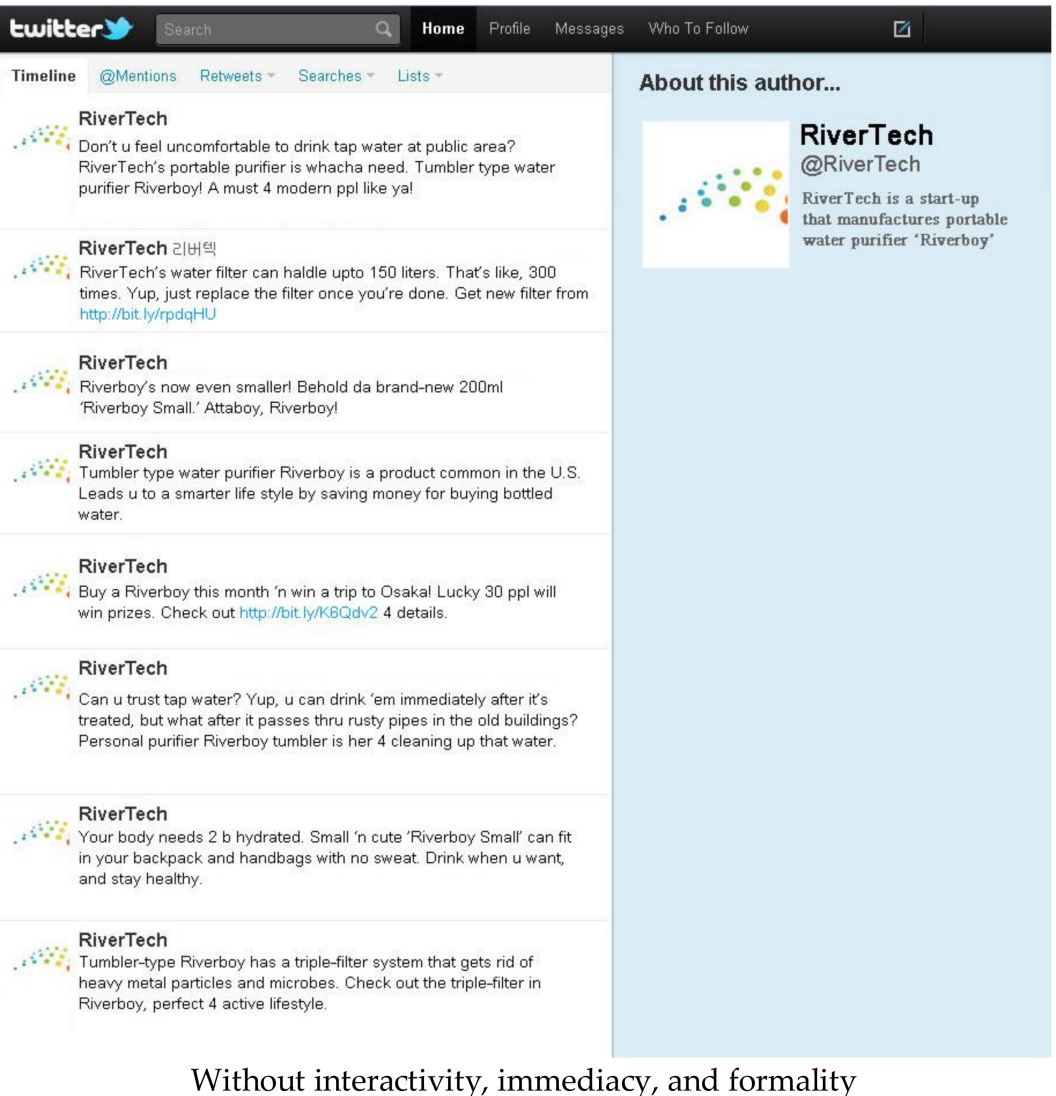

Without interactivity, immediacy, and formality

Figure 1. Examples of Corporate's Twitter Messages. 
Immediacy also had two levels, which was manipulated by the use of emoticons and the writer's personal, self-disclosing information included in the messages. For with-immediacy, four of the eight messages carried personal thoughts by the account manager unrelated to corporate activities (e.g., the weather is cold today, I do not like cold weather), combined with the use of "emoticons". For without-immediacy, none of the Tweet messages included personal thoughts or emoticons.

Firm size, the only between-subjects factor, was manipulated by using easily recognizable large companies with a strong presence in Korea for large firms (e.g., Philips, Canon, Nokia, and LG) and unknown fictional companies for SMEs, both from the information technology/high-tech sector in order to control for industry-specific effects. A description of the company was provided on the same screen with Tweet messages to ensure that subjects would notice whether the firm is an established, large one or an unknown SME.

\subsection{Procedure}

The subjects were exposed to one corporate Twitter profile at a time, showing eight Tweet messages per company, as shown in Figure 1. After being exposed to each stimulus, the subjects were asked to rate how much they agreed or disagreed with statements based solely on the Twitter profile not relying on their previous knowledge and/or experience regarding the following measures.

Interactivity: Perceived interaction intent of the firm on Twitter was measured by asking the subjects to rate on a seven-point Likert scale ( 1 for strongly disagree and 7 for strongly agree), their reaction to the statement, "The XYZ Company seems to have a strong willingness to communicate with their customers".

Formality: Perceived formality of the firm on Twitter was measured by asking the subjects to rate on a seven-point bipolar scale anchored with formal/informal.

Immediacy: Perceived immediacy of the firm on Twitter was measured by asking the subjects to rate on a seven-point bipolar scale anchored with socially close/distant.

Brand Attitude: Impression of the brand was measured using three seven-point bipolar scales anchored with "favorable/unfavorable", "good/bad", and "satisfactory/unsatisfactory" [38].

Corporate Trust: To measure the level of perceived corporate trust, the subjects were asked to rate their extent of agreement on seven-point Likert scales with the following statements: "I trust XYZ Company"; "The XYZ Company makes truthful claims"; "The XYZ Company is honest"; and, "I do believe what the XYZ Company tells me" [39]. The statements were presented in fully randomized order in the survey to reduce any bias.

Purchase Intention: The subjects were asked how likely it would be that they would consider buying the brand for their next purchase occasion. We used three seven-point bipolar scales, anchored with "very likely/very unlikely", probable/improbable", and "possible/impossible" [40].

\section{Analysis and Results}

\subsection{Manipulation Check, and Reliability and Validity of the Measurement}

The ANOVA (analysis of variance) results confirm that the manipulation was successful: two levels of interactivity ( $\mathrm{M}=4.14$ vs. $5.58, \mathrm{~F}=569.21, p<0.001$ ), formality $(\mathrm{M}=3.68$ vs. 4.36 , $\mathrm{F}=66.88, p<0.001)$, and immediacy $(\mathrm{M}=3.98$ vs. $5.25, \mathrm{~F}=333.65, p<0.001)$ showed significant differences as in Table 1. 
Table 1. ANOVA table of test results for manipulation check.

\begin{tabular}{|c|c|c|c|c|c|c|}
\hline & Independent Variable (IV) & $M_{\text {low IV }}$ (S.D.) & $M_{\text {high IV }}$ (S.D.) & $\mathbf{F}$ & $p$ & $\eta^{2}$ \\
\hline \multirow{3}{*}{ All (Subject $N=200$ ) } & Interactivity & $4.14(1.387)$ & $5.58(1.006)$ & 569.21 & $<0.001$ & 0.263 \\
\hline & Formality & $3.68(1.580)$ & $4.36(1.720)$ & 66.88 & $<0.001$ & 0.040 \\
\hline & Immediacy & $3.98(1.513)$ & $5.25(1.242)$ & 333.65 & $<0.001$ & 0.173 \\
\hline \multirow{3}{*}{ Large corp. (Subject $N=100$ ) } & Interactivity & $4.11(1.360)$ & $5.61(0.989)$ & 316.38 & $<0.001$ & 0.284 \\
\hline & Formality & $3.83(1.597)$ & $4.44(1.630)$ & 28.11 & $<0.001$ & 0.034 \\
\hline & Immediacy & $3.93(1.519)$ & $5.17(1.285)$ & 155.21 & $<0.001$ & 0.163 \\
\hline \multirow{3}{*}{ SMEs (Subject $N=100$ ) } & Interactivity & $4.16(1.415)$ & $5.55(1.023)$ & 255.35 & $<0.001$ & 0.243 \\
\hline & Formality & $3.53(1.551)$ & $4.28(1.805)$ & 39.25 & $<0.001$ & 0.047 \\
\hline & Immediacy & $4.03(1.508)$ & $5.32(1.196)$ & 179.55 & $<0.001$ & 0.184 \\
\hline
\end{tabular}

All latent variables are internally consistent, as Cronbach's alpha (the threshold value is Cronbach's alpha > 0.6) for brand attitude, corporate trust, and purchase intention are 0.89, 0.79, and 0.88 , respectively, as shown in Table 2. The average variance extracted (AVE) values are 0.74, 0.50 , and 0.71 for brand attitude, corporate trust, and purchase intention, respectively, which confirm adequate convergent validity, since the validity threshold is AVE $>0.50$.

Table 2. Reliability and Convergent Validity Statistics.

\begin{tabular}{|c|c|c|c|c|c|}
\hline Construct & Indicator & Indicator Loadings & Cronbach's Alpha & AVE & No. of Items \\
\hline \multirow{3}{*}{ Brand attitude } & BA1: unfavorable (1)-favorable (7) & 0.88 & 0.89 & 0.74 & 3 \\
\hline & BA2: bad (1)-good (7) & 0.91 & & & \\
\hline & BA3: unsatisfactory (1)-satisfactory (7) & 0.86 & & & \\
\hline \multirow{3}{*}{ Corporate trust } & $\begin{array}{l}\text { CT1: The XYZ Company makes } \\
\text { truthful claims }(1-7)\end{array}$ & 0.62 & 0.79 & 0.50 & 4 \\
\hline & CT2: I trust XYZ Company (1-7) & 0.52 & & & \\
\hline & CT4: The XYZ Company is honest $(1-7)$ & 0.93 & & & \\
\hline \multirow{3}{*}{$\begin{array}{l}\text { Purchase } \\
\text { intention }\end{array}$} & PI1: very unlikely (1)-very likely (7) & 0.88 & 0.88 & 0.71 & 3 \\
\hline & PI2: improbable (1)-probable (7) & 0.93 & & & \\
\hline & PI3: impossible (1)-possible (7) & 0.88 & & & \\
\hline
\end{tabular}

To verify the discriminant validity, which involves the items measuring only the intended construct, we checked whether the AVE for each construct was greater than the squared correlations $\left(\mathrm{r}^{2}\right)$ with the other constructs, as shown in Table 3.

Table 3. Discriminant Validity.

\begin{tabular}{cccc}
\hline & Brand Attitude & Corporate Trust & Purchase Intention \\
\hline Brand attitude & $\mathbf{0 . 7 4}$ & & \\
Corporate trust & 0.05 & $\mathbf{0 . 5 0}$ & \\
Purchase intention & 0.64 & 0.07 & $\mathbf{0 . 7 1}$
\end{tabular}

Note: The bold scores along the diagonal are the average variance extracted (AVEs) of the individual constructs and off-diagonal elements are the squared correlations between constructs. The diagonal elements should be greater than its corresponding off-diagonal elements.

\subsection{Structural Equation Model}

The structural equation model (SEM) was tested using AMOS 18.0. Eight structural paths were estimated for the model containing six constructs, and the standardized path coefficients $(\beta)$ are shown in Figure 2. In summary, all of the tested paths were statistically significant $(p<0.001)$, and all of the hypotheses were accepted. To test the goodness of fit of the proposed model, multiple measures were used: $\chi^{2}=1290.89, p<0.001 ; \chi^{2} / \mathrm{df}=22.65 ; \mathrm{GFI}=0.90$; AGFI $=0.85 ; \mathrm{CFI}=0.91 ; \mathrm{NFI}=0.91$; $\mathrm{IFI}=0.91 ; \mathrm{TLI}=0.88$. All of the measures consistently suggest that our proposed model provides an acceptable fit. As in multiple regressions, squared multiple correlations $\left(R^{2}\right)$ indicate the amount 
of variance explained by exogenous variables. To prove the effectiveness of our proposed structural model, squared multiple correlations $\left(R^{2}\right)$ were computed: 21.3 for brand attitude, 22.8 for corporate trust, and 64.5 for purchase intentions.

As shown in Table 4, corporate trust is stronger when the structural features (interactivity, formality, and immediacy) in social media messages are perceived to exist within the message $(\mathrm{H} 1, \mathrm{H} 2$, $\mathrm{H} 3$ are all supported). In terms of relative influence, formality is the highest $(\beta=0.36, p<0.001)$ and immediacy is the lowest $(\beta=0.16, p<0.001)$. Likewise, findings confirm that brand attitude is more positive when the structural features mentioned above are perceived (RQ1, RQ2, RQ3 are all significant with positive results). In terms of relative influence, However, the relative influence is different from corporate trust: interactivity is the highest $(\beta=0.31, p<0.001)$, and immediacy is the lowest $(\beta=0.18, p<0.001)$. These results provide empirical support for the phenomenon that companies increasingly recognize in terms of the importance of active two-way communication via social media. Along with the effect of perceived interactivity on brand attitude, we confirm that customers have stronger corporate trust when companies disseminate messages with formality. While its impact is smaller than interactivity and formality, the findings also support the notion that immediacy is necessary in order to enhance brand attitude and corporate trust. In addition, the model also confirms that brand attitude and corporate trust positively influence purchase intention.

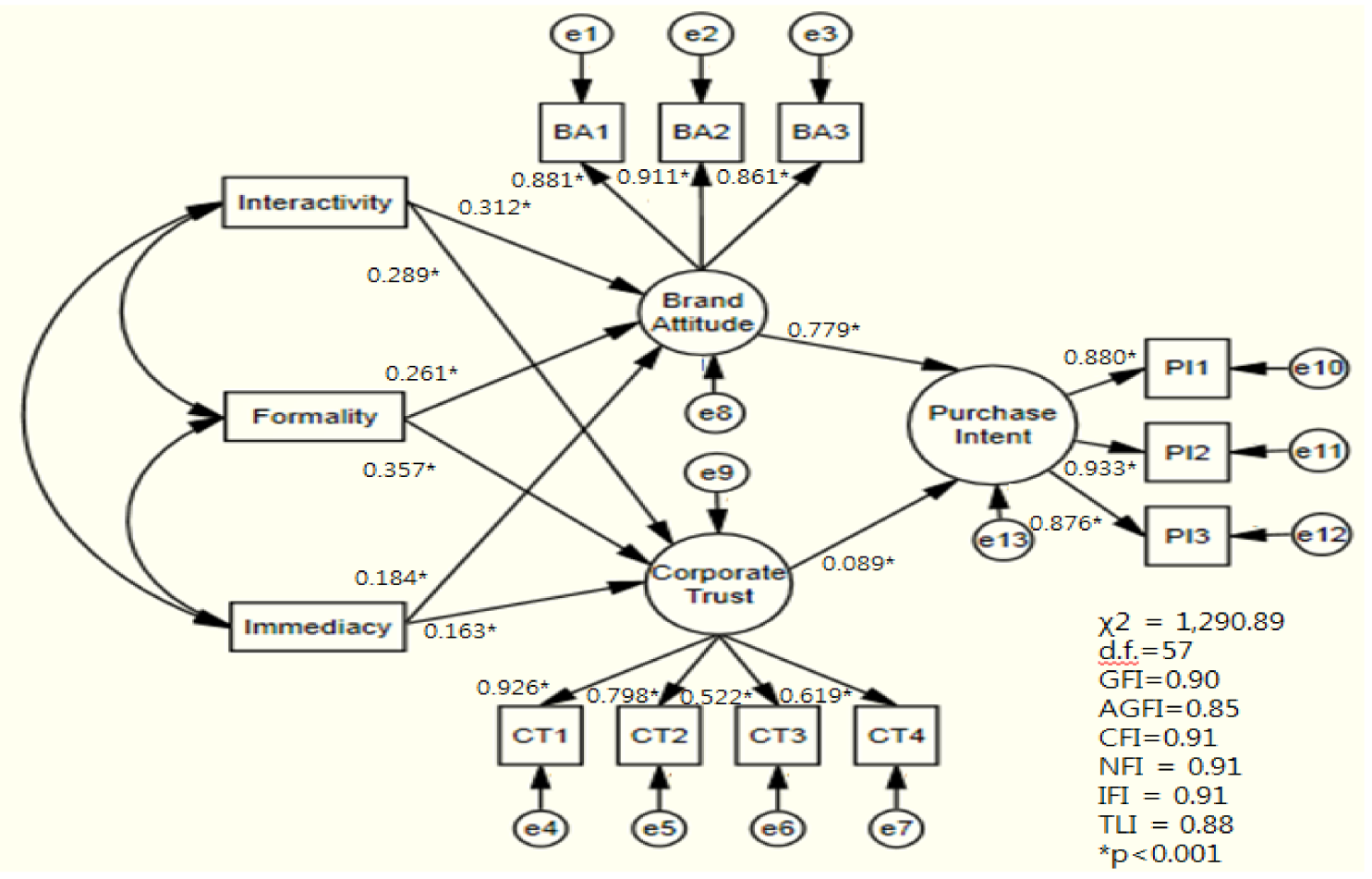

Figure 2. Estimated Model (standardized estimates).

In the structural equation model, the effects from one variable to other variables can be direct or indirect. So far, we discussed the direct effects. In the proposed structural model, there exist indirect effects, which come from the two variables connected by more than one path (e.g., interactivity $\rightarrow$ brand attitude $\rightarrow$ purchase intention). When the paths from each of the message attributes (interactivity, formality, and immediacy) in social media through brand attitude and corporate trust to purchase intention are indirect effects, the total effect of interactivity on purchase intention is $0.269(p<0.001)$, that of formality on purchase intention is $0.235(p<0.001)$, and that of immediacy on purchase intention is $0.158(p<0.001)$. That is, the return on one unit of interactivity is the highest, compared with one unit input of either formality or immediacy. 
Table 4. Hypotheses and Research Question Testing.

\begin{tabular}{ccccccc}
\hline & \multicolumn{2}{c}{ Hypothesis } & & Standardized Path Coefficient $(\boldsymbol{\beta})$ & $p$-Value & Result \\
\hline H1 & Interactivity & $\rightarrow$ & Corporate trust & 0.289 & $<0.001$ & Accepted \\
H2 & Formality & $\rightarrow$ & Corporate trust & 0.357 & $<0.001$ & Accepted \\
H3 & Immediacy & $\rightarrow$ & Corporate trust & 0.163 & $<0.001$ & Accepted \\
RQ1 & Interactivity & $\rightarrow$ & Brand attitude & 0.312 & $<0.001$ & Accepted \\
RQ2 & Formality & $\rightarrow$ & Brand attitude & 0.261 & $<0.001$ & Accepted \\
RQ3 & Immediacy & $\rightarrow$ & Brand attitude & 0.184 & $<0.001$ & Accepted \\
H4a & Brand attitude & $\rightarrow$ & Purchase intention & 0.779 & $<0.001$ & Accepted \\
H4b & Corporate trust & $\rightarrow$ & Purchase intention & 0.089 & $<0.001$ & Accepted \\
\hline
\end{tabular}

Note: All of the regression weight reported here are significantly different from zero at the 0.001 level (two-tailed).

A multi-group structural equation model was used to test the differences of paths in two groups: large firms and SMEs, as shown in Table 5. Based on the multi-group comparison results from AMOS 18.0, the unconstrained model (M1) and the invariant structural weight model (M2) are compared: the structural weights for the models are not significantly different.

Table 5. Multi-group Comparison Models.

\begin{tabular}{lccccccc}
\hline & Model & $\chi^{2}$ & df & $\chi^{2} / \mathbf{d f}$ & $\Delta$ df & $\Delta \chi^{2}$ & $p$ \\
\hline M1 & Unconstrained & 1361.24 & 114 & 11.94 & - & - & - \\
M2 & Invariant structural weight & 1383.40 & 129 & 10.72 & 15 & 22.17 & 0.104 \\
\hline
\end{tabular}

While large firms and SMEs are not different at the model level, they may be different at the path level. Table 6 provides pairwise parameter comparisons, where all paths except the path between corporate trust and purchase intention (corporate trust $\rightarrow$ purchase intention) are significant at the 0.001 level. The impact of interactivity on corporate trust is significantly different $(p<0.05): 0.338$ for large firms and 0.243 for SMEs (RQ4a), though the impact of interactivity on brand attitude does not differ by firm size (RQ4b).

Although the impact of formality and immediacy on brand attitude and corporate trust are not different across large and SMEs (RQ5 and RQ6), the impact of brand attitude and corporate trust on purchase intention are different for large firms and SMEs (RQ7). This suggests communication techniques should be different for large firms and SMEs for optimal results, which is further discussed in the following section.

Table 6. Multi-group Pairwise Parameter Comparisons (standardized estimates).

\begin{tabular}{|c|c|c|c|c|c|c|c|}
\hline Research Questions & & Paths & & $x^{2}$ & $\Delta \chi^{2}$ & Large & SMEs \\
\hline RQ4a & Interactivity & $\rightarrow$ & Corporate Trust & 1378.82 & $4.586^{*}$ & $0.338^{* * *}$ & $0.243^{* * *}$ \\
\hline RQ4b & Interactivity & $\rightarrow$ & Brand Attitude & 1383.28 & 0.128 & $0.296^{* * *}$ & $0.329 * * *$ \\
\hline RQ5a & Formality & $\rightarrow$ & Corporate Trust & 1381.27 & 2.135 & $0.313^{* * *}$ & $0.384^{* * *}$ \\
\hline RQ5b & Formality & $\rightarrow$ & Brand Attitude & 1382.94 & 0.463 & $0.227 * * *$ & $0.282 * * *$ \\
\hline RQ6a & Immediacy & $\rightarrow$ & Corporate Trust & 1381.05 & 2.355 & $0.211 * * *$ & $0.133^{* * *}$ \\
\hline RQ6b & Immediacy & $\rightarrow$ & Brand Attitude & 1382.90 & 0.503 & $0.176^{* * *}$ & $0.213^{* * *}$ \\
\hline
\end{tabular}

\section{Conclusions and Discussion}

The purpose of the current research is to apply findings from communication science to explore the impact of structural features used in corporate social media messages on consumers' attitude and behavioral intent. The model proposed demonstrates that different types of structural features indeed affect brand attitude and corporate trust, which ultimately lead to changes in firm performance on the 
basis of purchase intention. The findings from this study suggest that companies should engage in active dialogues with their customers, not only to provide adequate information to involved customers, but also to convey the idea that companies are willing to communicate with their customers for their sustainable growth. Companies should also avoid using informal expressions in their communications, and should promote to customers a perceived sense of closeness to the firm. Particularly with linguistic formality, the literature suggests that formal communication increases social distance between people who are engaged [41,42]. However, given that a company is not a person, customers are likely to have different expectations in the communication process. It might be the case that customers want to keep the company at arm's length, rather than getting too close to it.

The only occasion when firm size served as a significant moderating factor for the impact of structural features was interactivity affecting corporate trust. Results for RQ4a shows that the impact of interactivity on corporate trust was larger for large corporates than for SMEs. An individual might expect large corporates not to "talk to" individuals while they expect that SMEs would, and when large corporates do so, people may value it more than when SMEs do. Firm size as a moderator played a significant role on how corporate trust and brand attitude affects purchase interest. Results for RQ7a show that the impact of corporate trust on purchase intention for large corporates is significant but small, while that for SMEs is larger. This makes sense since large corporates are generally seen as trustable, and the impact from additional trust built through social media may be marginal. But for unknown SMEs, corporate trust is critical for convincing customers to purchase their product. Since the experiment's participants saw the SMEs for the first time during the experiment, the body of trust was built while they were exposed to the social media messages, and nowhere else. This implies that SMEs with little to no presence in the market should pay more attention on building corporate trust than large corporates do.

The main managerial implication from this research is, for marketing communications, that small details, such as structural features in messages, can have significant effects on customers' attitudes and purchase intention. Although Twitter was used as a context for this study, virtually all marketing communication using text, from e-mails to bulletin boards on the Web, may apply the findings from this study. Social media (e.g., Facebook, Linkedin) in particular encourages any potential consumers to see messages, including their interaction with other people. For this reason, it is a good idea to have guidelines for communicating with customers that cover such details. The findings can also be applied to mobile advertising, which still relies heavily on SMS (Simple Message Service) and delivers messages in a text-only format, similar to the settings for this study.

Another managerial implication is for SMEs. Social media are believed to provide a good marketing platform for SMEs by providing access to huge audiences at a very low cost. The findings from this study suggest that brand attitude and corporate trust have larger impacts on purchase intention for SMEs than large firms. Especially, the impact of corporate trust on purchases was very large for SMEs, compared to that for large firms. Building trust generally requires significant investment [43]. Although such investment may be hard for SMEs with few resources, SMEs may be able to get a head start by forming trust with initial impressions on social media, or any other media where interaction with customers takes place. While formality and immediacy of messages were not significantly different for large firms and SMEs, interactivity had different impacts when moderated by firm size. Given that applying structural features, or manipulating the writing style of messages cost little, SMEs can take advantage of the fact that all three message attributes can be used to positively influence customers' attitudes, and they can increase their activity on social media to compete with large competitors.

One limitation of this study was that only Twitter was used as the context for collecting data. Twitter was selected for this study not only because its popularity, but because it has an emphasis on delivering text-only messages (Facebook, another popular social media, tends to have more emphasis on sharing images and videos than Twitter does). While the use of this particular medium did help the study to focus on the effects of language used in the message, it still leaves questions as to whether 
the use of different fonts, animated images, or sound effects would have had a different impact. Whether uploading personal images of the social media operators would have also had a positive impact from social immediacy, as it "puts a face" on a person instead of remaining an anonymous employee, is another question that remains unanswered. Since Facebook and many other popular social media platforms allow users to upload rich, multimedia content, future studies should take this into account for developing research questions. In addition, it is possible that participants' responses are influenced by their product category involvement or prior attitudes toward corporates (large corporates are selected from the existing top corporates). In order to avoid this, large corporates which were receiving negative news coverage at the time were excluded, and products/services that are popular among college students were selected. Nevertheless, it still is a concern that future studies should consider. Lastly, a limitation comes from the cultural homogeneity of our subjects, as we collected the data in Korea. For countries with different cultures and languages, the results may vary. This opens opportunities for future research to study this topic from a cross-cultural perspective.

Acknowledgments: This research has been supported by Faculty Research Funding Program from KAIST College of Business, Korea Advanced Institute of Science and Technology, from 2012 to 2013.

Author Contributions: Byungho Park took the main role in conceiving and designing the experiment; Moon Young Kang took the main role in data analysis and drawing managerial implications from the results; Overall, both authors made equal contributions to the study and writing of this article.

Conflicts of Interest: The authors declare no conflict of interest.

\section{References}

1. Choi, H. Broadcasting and telecommunications industries in the convergence age: Toward a sustainable public-centric public interest. Sustainability 2018, 10, 544. [CrossRef]

2. Barnes, N.G.; Lescault, A.M.; Wright, S. 2013 fortune 500 are bullish on social media: Big companies get excited about google+, instagram, foursquare and pinterest. In Center for Marketing Research; University of Massachusetts: Dartmouth, MA, USA, 2013.

3. Grönroos, C. Service Management and Marketing: A Customer RelationshipMmanagement Approach; Wiley: New York, NY, USA, 2000.

4. Lang, A. The limited capacity model of mediated message processing. J. Commun. 2000, 50, 46-70. [CrossRef]

5. Carson, D.; Gilmore, A. Marketing at the Interface: Not 'What' but 'How'. J. Mark. Theory Pract. 2000, 8, 1-7. [CrossRef]

6. Doney, P.M.; Cannon, J.P. An examination of the nature of trust in buyer-seller relationships. J. Mark. 1997, 61, 35-51. [CrossRef]

7. Batrancea, I.; Morar, I.; Masca, E.; Catalin, S.; Bechis, L. Econometric modeling of SME performance. Case of romania. Sustainability 2018, 10, 192. [CrossRef]

8. Lang, A.; Borse, J.; Wise, K.; David, P. Captured by the world wide web orienting to structural and content features of computer-presented information. Commun. Res. 2002, 29, 215-245. [CrossRef]

9. Van Dijk, J. The Network Society: Social Aspects of New Media; Sage: Thousand Oaks, CA, USA, 2006.

10. Bose, R. Customer relationship management: Key components for it success. Ind. Manag. Data Syst. 2002, 102, 89-97. [CrossRef]

11. Livingstone, S. New media, new audiences? New Media Soc. 1999, 1, 59-66. [CrossRef]

12. Downes, E.J.; McMillan, S.J. Defining interactivity a qualitative identification of key dimensions. New Media Soc. 2000, 2, 157-179. [CrossRef]

13. Lindström, M.; Andersen, T.F. Brand Building on the Internet; Hardie Grant Books: Melbourne, Australia, 2000.

14. Hawes, J.M.; Mast, K.E.; Swan, J.E. Trust earning perceptions of sellers and buyers. J. Pers. Sell. Sales Manag. 1989, 9, 1-8.

15. Delgado-Ballester, E. Applicability of a brand trust scale across product categories: A multigroup invariance analysis. Eur. J. Mark. 2004, 38, 573-592. [CrossRef]

16. Jarvenpaa, S.L.; Leidner, D.E. Communication and trust in global virtual teams. J. Comput. Mediat. Commun. 1998, 3, 1-29. [CrossRef] 
17. Bell, A. Language style as audience design in sociolinguistics. In Sociolinguistics: A Reader and Course book; Coupland, N., Jaworski, A., Eds.; St. Martin's Press: New York, NY, USA, 1997; pp. 240-250.

18. Wierzbicka, A. Cross-Cultural Pragmatics: The Semantics of Human Interaction; Walter de Gruyter: Berlin, Germany, 2003.

19. Leech, G.N.; Leech, G. Principles of Pragmatics; Longman: London, UK, 1983; Volume 285.

20. Hyland, K. Exploring corporate rhetoric: Metadiscourse in the CEO's letter. J. Bus. Commun. 1998, 35, $224-244$. [CrossRef]

21. Sheth, J.N.; Parvatlyar, A. Relationship marketing in consumer markets: Antecedents and consequences. J. Acad. Mark. Sci. 1995, 23, 255-271. [CrossRef]

22. Mehrabian, A. Some referents and measures of nonverbal behavior. Behav. Res. Methods Instrum. 1968, 1, 203-207. [CrossRef]

23. Gunawardena, C.N.; Zittle, F.J. Social presence as a predictor of satisfaction within a computer-mediated conferencing environment. Am. J. Distance Educ. 1997, 11, 8-26. [CrossRef]

24. Argyle, M. Bodily Communication; Taylor \& Francis: Abingdon, UK, 1988; Volume 581.

25. Walther, J.B.; D'Addario, K.P. The impacts of emoticons on message interpretation in computer-mediated communication. Soc. Sci. Comput. Rev. 2001, 19, 324-347. [CrossRef]

26. Hwang, Y.; Kim, D.J. Customer self-service systems: The effects of perceived web quality with service contents on enjoyment, anxiety, and E-trust. Decis. Support Syst. 2007, 43, 746-760. [CrossRef]

27. Barnes, J.G. Closeness, strength, and satisfaction: examining the nature of relationships between providers of financial services and their retail customers. Psychol. Mark. 1997, 14, 765-790. [CrossRef]

28. Bai, B.; Law, R.; Wen, I. The impact of website quality on customer satisfaction and purchase intentions: Evidence from Chinese online visitors. Int. J. Hosp. Manag. 2008, 27, 391-402. [CrossRef]

29. Esch, F.R.; Langner, T.; Schmitt, B.H.; Geus, P. Are brands forever? How brand knowledge and relationships affect current and future purchases. J. Prod. Brand Manag. 2006, 15, 98-105. [CrossRef]

30. Homer, P.M. The mediating role of attitude toward the Ad: Some additional evidence. J. Mark. Res. 1990, 27, 78-86. [CrossRef]

31. Chu, W.; Choi, B.; Song, M.R. The role of on-line retailer brand and infomediary reputation in increasing consumer purchase intention. Int. J. Electron. Commer. 2005, 9, 115-127.

32. Keh, H.T.; Xie, Y. Corporate reputation and customer behavioral intentions: The roles of trust, identification and commitment. Ind. Mark. Manag. 2009, 38, 732-742. [CrossRef]

33. Bakker, M.; Leenders, R.T.A.; Gabbay, S.M.; Kratzer, J.; van Engelen, J.M. Is trust really social capital? Knowledge sharing in product development projects. Learn Organ. 2006, 13, 594-605. [CrossRef]

34. Goldsmith, R.E.; Lafferty, B.A.; Newell, S.J. The influence of corporate credibility on consumer attitudes and purchase intent. Corp. Reput. Rev. 2000, 3, 304-318. [CrossRef]

35. Gilmore, A.; Carson, D.; Grant, K. SME marketing in practice. Mark. Intell. Plan. 2001, 19, 6-11. [CrossRef]

36. Jarvenpaa, S.L.; Tractinsky, N.; Saarinen, L. Consumer trust in an internet store: A cross-cultural validation. J. Comput. Mediat. Commun. 1999, 5. [CrossRef]

37. Eom, K. A study on the speech level of listeners-honorific for modern Korean language. Int. J. Lang. Lit. 2002, 30, 79-98.

38. Lafferty, B.A.; Goldsmith, R.E. Corporate credibility's role in consumers' attitudes and purchase intentions when a high versus a low credibility endorser is used in the Ad. J. Bus. Res. 1999, 44, 109-116. [CrossRef]

39. Newell, S.J.; Goldsmith, R.E. The development of a scale to measure perceived corporate credibility. J. Bus. Res. 2001, 52, 235-247. [CrossRef]

40. Yi, Y. A critical review of consumer satisfaction. Rev. Mark. 1990, 4, 68-123.

41. Park, J. Linguistic Politeness and Face-work in Computer Mediated Communication, Part 2: An application of the theoretical framework. J. Assoc. Soc. Inf. Sci. Technol. 2008, 59, 2199-2209. [CrossRef] 
42. Westbrook, L. Chat reference communication patterns and implications: Applying politeness theory. J. Doc 2007, 63, 638-658. [CrossRef]

43. Kim, H.W.; Xu, Y.; Gupta, S. Which is more important in internet shopping, perceived price or trust? Electron. Commer. Res. Appl. 2012, 11, 241-252. [CrossRef] 